\title{
FEASIBILITY STUDY OF A WATER HYDRAULIC POSITIONING SYSTEM IN PROCESS VALVES
}

\author{
Tapio VIRVALO \\ IHA, Tampere University of Technology, Finland \\ P.O.Box 589, 33101 Tampere \\ Tel. $-358-3-3652262$, Fax. $-358-3-3652240$ \\ e-mail virvalo@cc.tut.fi
}

\begin{abstract}
Pneumatic positioning actuators are commonly used to control process control valves in petroleum, chemical, and paper industries. Pneumatics has many advantages in these applications, but there are also drawbacks. The purpose of this study is to find out if low-pressure water hydraulics can be used in the control applications of process valves. Low-pressure water is available in some process industrial applications. However, water hydraulics is considered very expensive technology. Some feasibility studies claim, though, that low-pressure water hydraulics is relatively cost effective. In this paper advantages and drawbacks of pneumatic and low-pressure water hydraulic solutions are discussed. Design, modeling, simulation, and experimental results of the low-pressure water hydraulic control of a process valve are presented. The performance requirements of a low-pressure water hydraulic servo valve are studied in simulations and experimental tests. Evaluation of the feasibility of water hydraulics in positioning applications of process valves is discussed.
\end{abstract}

\section{KEYWORDS}

Water hydraulics, low pressure water hydraulics, position servo

\section{INTRODUCTION}

Pneumatic positioning actuators are commonly used to control process control valves such as in petroleum, chemical, and paper industries. A commercial pneumatic positioning actuator is depicted in Figure 1 as an example. Pneumatics has many advantages in these applications, but there are also drawbacks. The main advantages are easy assembly and cost effectiveness. The most significant drawbacks are poor performance and large size. The purpose of this study is to find out if low-pressure water hydraulics can be used in the control applications of process valves. Low-pressure water is available in some process industrial applications. However, high-pressure water hydraulics is considered very expensive technology. Some studies claim, though, that low-pressure water hydraulics is relatively cost effective [1].

The idea is to replace the pneumatic cylinder actuator with a low-pressure water hydraulic cylinder actuator in the positioning system of process valves. The supply pressure varies typically between $0.14 \ldots 0.8 \mathrm{MPa}$ in pneumatic applications. This means that the size of some pneumatic actuators is quite large. The supply pressure in this lowpressure water hydraulic application is figured to be $1 . . .3$ 
$\mathrm{MPa}$, because it might be available in some process industry applications.

\section{GOALS OF STUDY}

The goal is to find out if it is possible to replace pneumatic actuators with low-pressure water hydraulic actuators in the control application of process valves. Since there is no previous experience or knowledge concerning this kind of a water hydraulic application an experimental study was carried out. The following goals were set:

- To ensure that it is possible to realize low-pressure water hydraulic systems in this application.

- To find out if the performance criterion applied to pneumatic positioning systems can be fulfilled.

- To specify the specifications of the valid components of the system.

- To specify the performance requirements of the control.

- To specify the water hydraulic power unit.

- To gain experience in low-pressure water hydraulic servo system applications.

\section{PROBLEMS OF STUDY}

The main problems were to find suitable components and find some knowledge about this kind of low-pressure water hydraulic application. The required main components were: a process valve with matching positioning unit, a position sensor, a servo valve, a water hydraulic power unit with needed accessories, and a controller. The basic idea was that there should not be any major problems in fulfilling the specification as far as controlling is concerned, because they can be fulfilled with pneumatics. On the other hand there were questions about the influence of friction forces, leakages,_and the quality of components. There was no knowledge about the reliability and life cycle of this kind of application.

\section{SPECIFICATIONS OF SYSTEM}

A normal process valve with a standard pneumatic

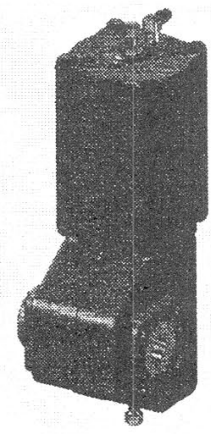

Figure 1. Pneumatic positioner actuator was used in the tests, Figure 1. A pneumatic positioning system was replaced with a low-pressure water hydraulic system with the following specifications:

- Cylinder 80/20-76 (piston diameter/rod diameterstroke $[\mathrm{mm}]$ ), original pneumatic cylinder 125/20-76.

- Average friction force of cylinder and process valve $4000 \mathrm{~N}$.

- Inertia load $10 \mathrm{~kg}$ (piston, mechanism, and the moving part of a process valve).

- Servo valve.

- Nominal volume flow $19 \mathrm{l} / \mathrm{min}$.

- Nominal pressure drop/control notch 3.5 MPa.

- $-90^{\circ}$ band width $600 \mathrm{rad} / \mathrm{s}$.

- Hysteresis $<3 \%$.

The performance specifications were set as follows:

- The minimum stroke time for the full stroke $2 \mathrm{~s}$.

- The average piston velocity $38 \mathrm{~mm} / \mathrm{s}$.

- The allowed dead band $<0.06 \%$ corresponding the position error of the piston $0.045 \mathrm{~mm}$.

- The required position resolution $0.04 \%$ corresponding the motion of the piston $0.03 \mathrm{~mm}$.

- The settling time without the valve saturation $<0.4 \mathrm{~s}$.

The specifications of the control system were as follows:

- The position sensor was installed on the turning axis of the process valve.

- The differential capacitive angle sensor with the output $4 \ldots 20 \mathrm{~mA}$.

- The output of the position sensor was scaled from 0 $\mathrm{mm}$ (process valve closed) to $76 \mathrm{~mm}$ (process valve open).

- The controller was realized on the PC with the dedicated DSP-card.

- The ADC and DAC were 12 bits.

- The sampling time was $2 \mathrm{~ms}$.

\section{SYSTEM MODEL}

Since it was obvious that the influence of some factors has to be studied in simulation, a non-linear model was created. This model was verified in the initial stage of the study with open loop measurements.

The following features are included in the non-linear model:

- Actuator.

- Friction forces considering also the flexibility of the piston seals.

- Effective bulk module as a function of the piston position.

- Small amount of air in the system (typical in water hydraulics).

- Load force as a non-linear function of the piston position.

- Servo valve.

- Turbulent volume flow.

- Leakage. 
- Hysteresis.

- Overlaps.

- Dynamics as a second order system.

- Inside saturation of the valve.

- Pipes.

- Four order transfer unction.

- Controller.

- Non-linear P- and State controller.

- Sampling time

Figure 2 and 3 show, as examples, both the measured and simulated piston forces in the open loop response of the full stroke as well as the closed loop position error step response. The simulated result matches the measured response reasonably well. The oscillation due to the long supply and tank pipes at the end of the stroke also matches quite well, Figure 2.

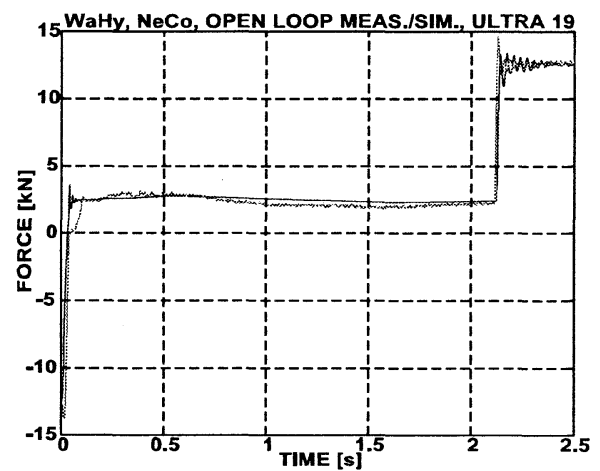

Figure 2. Measured and simulated force when process valve is opened.

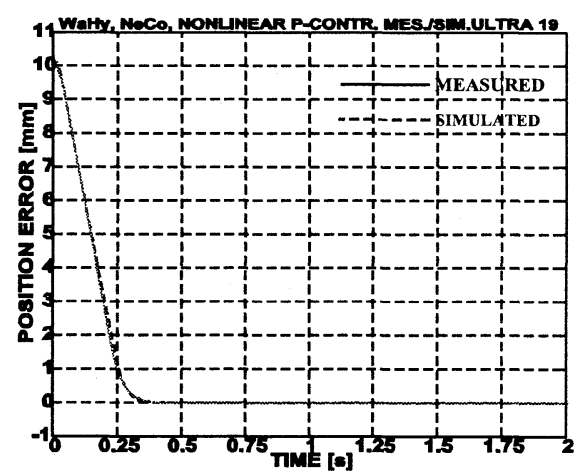

Figure 3. Measured and simulated position error step response

Based on model verifications the following conclusions can be made:

- Good basic behavior of the model..

- Some uncertainties in the non-linear model.

- The non-linearities between the piston motion and the valve axis.

- The non-linearities between the piston force and the axis torque.

- Friction forces.
- The flexibility of piston seals.

However, the measured and simulated results match each other so well that the model can be used in the study the system behavior.

\section{EXPERIMENTAL TESTS}

Experimental tests were carried out with pure water hydraulics. All components were commercial. The water hydraulic power supply was taken from the main power unit of the laboratory, and the supply pressure was set with the pressure relief valve. There was also an accumulator in the supply line. The diagram of the test system is depicted in Figure 4. The servo valve was installed with $100 \mathrm{~mm}$ length pipes to the actuator. The supply pressure was constant in practice, even though the power unit has been designed for $40 \mathrm{MPa}$. The position sensor and two pressure sensors were used.

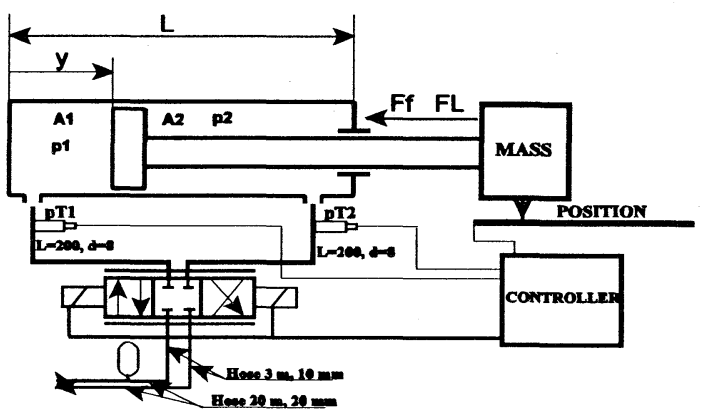

Figure 4. Diagram of test system.

\section{INITIAL TESTS}

In order to make sure that the system worked correctly some open loop measurements were carried out. Figure 5

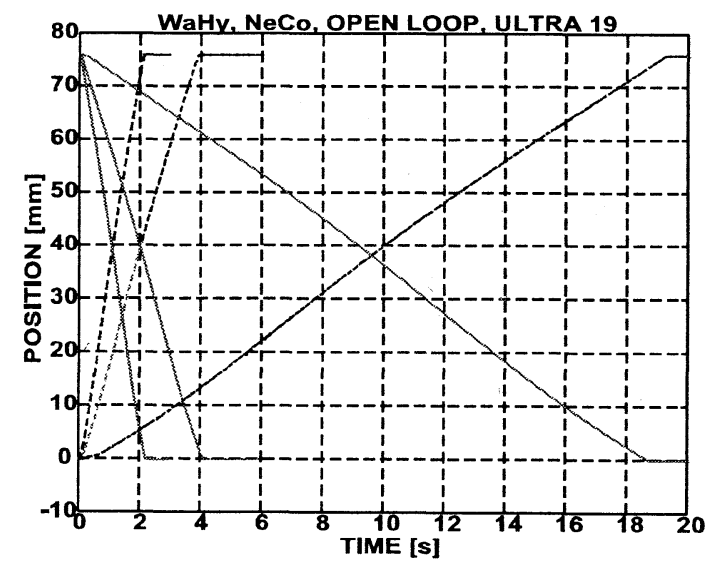

Figure 5. Open loop position responses with valve control signals $+/-100,50$, and $10 \%$.

shows the responses of the full stroke with different control signals. The full stroke takes a little more than $2 \mathrm{~s}$ 
because the supply pressure was $2.7 \mathrm{MPa}$ during the test. The full stroke-time can be achieved if the supply pressure is $3.5 \mathrm{MPa}$. Figure 6 shows the quality of the position measurement signal. Since no filtering was used, the average variation in the position signal was $\pm 0.01 \mathrm{~mm}$.

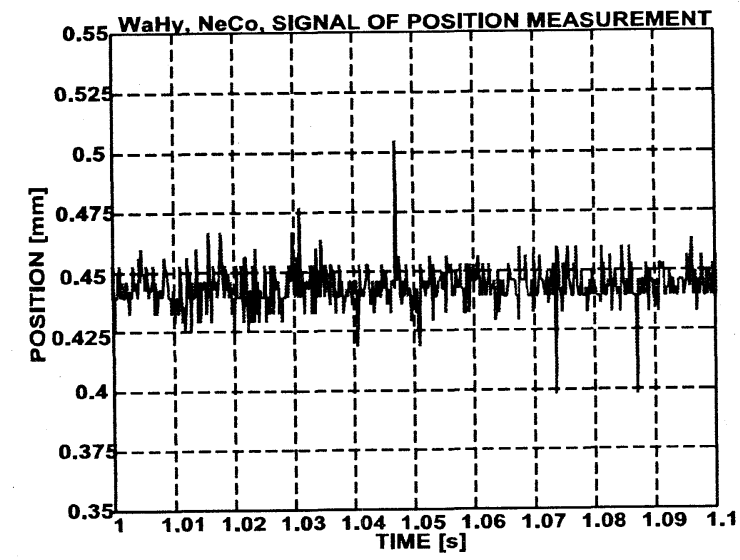

Figure 6 Quality of position sensor signal.

\section{PERFORMANCE TESTS}

Because the specifications of the process valve positioner specify the performance of step responses, the following step responses were carried out. Figures 7, 8, 9 and 10 show the position error responses in both directions with the different stroke lengths.

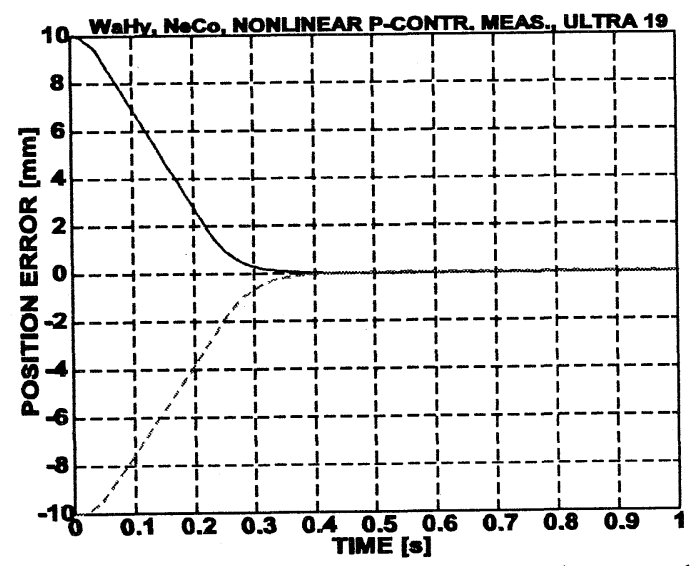

Figure 7. Position error step responses, strokes are \pm 10 $\mathrm{mm}$.

In these tests the position servo system with a non-linear P-controller was applied. All responses fulfill the required positioning accuracy of $0.045 \mathrm{~mm}$. The required settling time was also fulfilled in all responses. The dynamic behavior of all responses is excellent. There are no serious oscillations or overshoots.

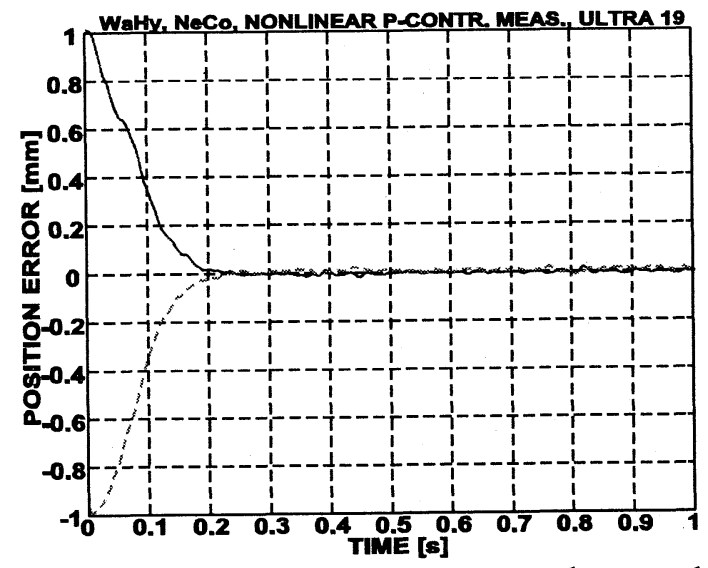

Figure 8. Position error step responses, strokes are \pm 1 $\mathrm{mm}$.

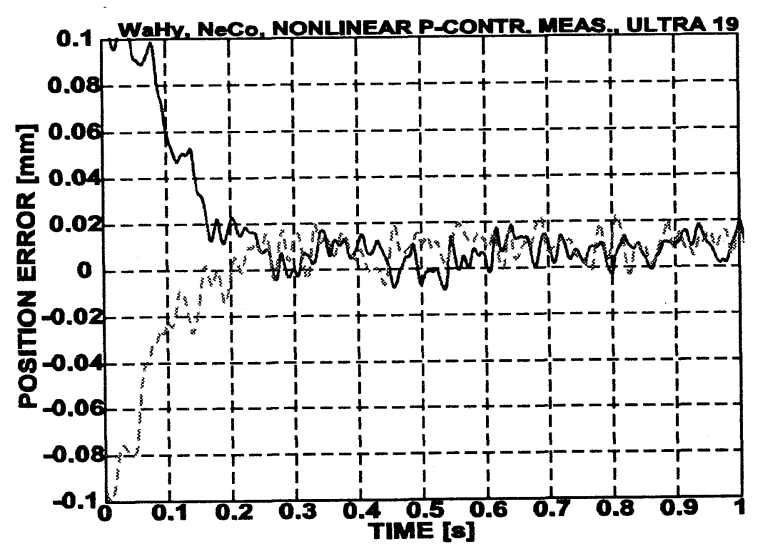

Figure 9. Position error step responses, strokes are \pm 0.1 $\mathrm{mm}$.

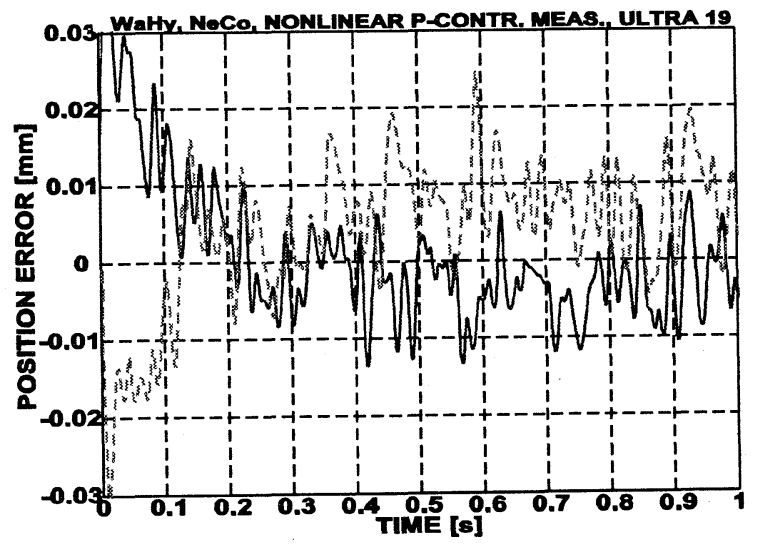

Figure 10. Position error step responses, strokes are $\pm 0.03 \mathrm{~mm}$.

The follow-up capability and the hysteresis of the positioning system were studied in the following way. The reference signal was a triangle wave from $40 \mathrm{~mm}$ to 47.6 
$\mathrm{mm}$ and back to $40 \mathrm{~mm}$ with the cycle time of $100 \mathrm{~s}$. The results are presented in Figure 11 and Figure 12.

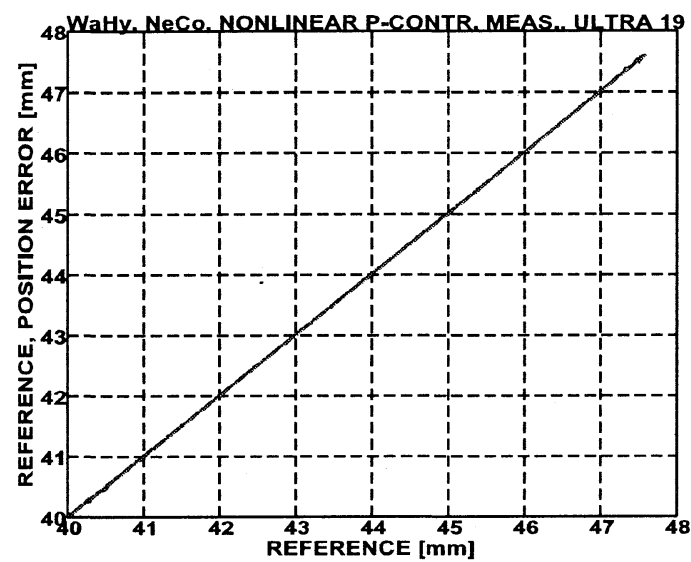

Figure 11. Hysteresis

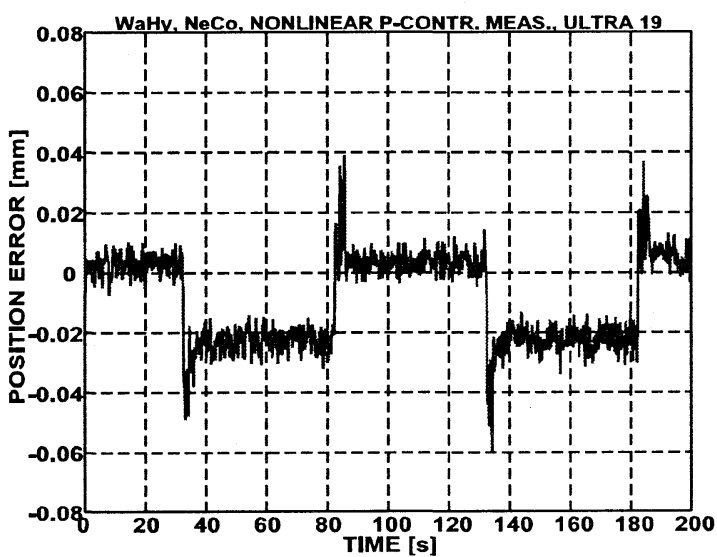

Figure 12. Position error when reference signal is triangle wave.

The following conclusions can be made according to the results in Figures 11 and 12:

- The follow-up error is less than $<0.03 \mathrm{~mm}(0.04 \%)$ in steady state, but when the direction of the reference signal changes there is a brief position error of 0.06 $\mathrm{mm}(0.08 \%)$.

- The hysteresis is $0.04 \mathrm{~mm}(0.05 \%)$.

The resolution of the positioning system was studied in the following way. The reference signal was a step ramp with a $0.02 \mathrm{~mm}$ step both directions. The duration of each step was 2 s.. The results are presented in Figure 13. The following conclusions can be made according to the result in Figures 13:

- Position servo responses to the changes of $0.02 \mathrm{~mm}$ in the reference signal.

- The settling time is not exact because of disturbances in the position feedback signal.

- Position error is less than $0.03 \mathrm{~mm}$ in the whole stroke range.

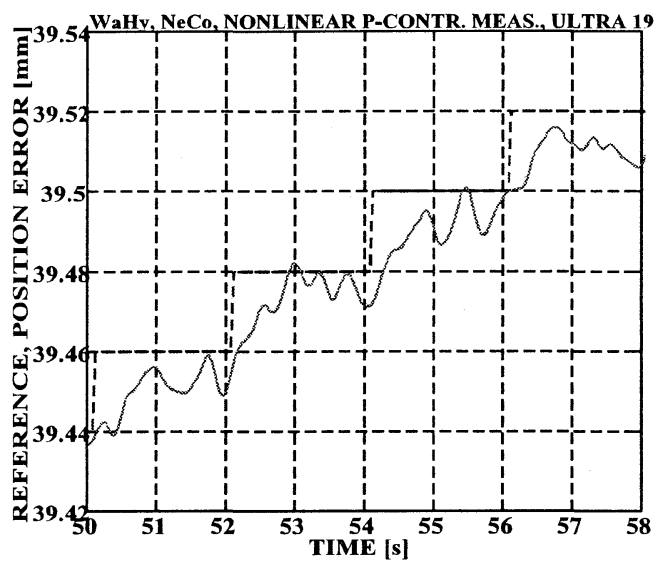

Figure 13 Zoomed position response to the $0.02 \mathrm{~mm}$ steps.

According to these measurements the following conclusions can be made:

- Almost all required specifications can be fulfilled.

- The full stroke-time is $10 \%$ too long.

- The full stroke-time can be shortened by increasing the supply pressure $(2.7-->3.5 \mathrm{MPa})$ without any other influence on performance.

- There is remarkable noise in the position feedback signal. It can be eliminated with a suitable filter.

- The airing of the system is extremely important. There must be airing point in the cylinder connections.

- Experimental tests were conducted over too short a term, as only about 12000 strokes were carried out during tests.

\section{COMPARISON TO PNEUMATIC POSITIONER}

The steady state and dynamic specifications of the positioner systems of process valve are presented in [2]. Important control performance criterion parameters are presented in Figure 14.

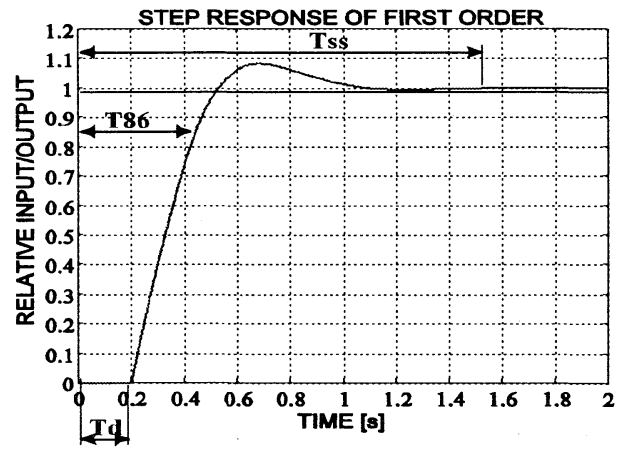

Figure 14 Definition of performance criterion parameters.

The parameter values for the most demanding cases are; $\mathrm{Td}=0.1 \mathrm{~s}, \mathrm{~T} 860.4 \mathrm{~s}$ and $\mathrm{Tss}=1 \mathrm{~s}$. In addition the 
following specifications are valid: dead band $0.06 \%$, step resolution $0.04 \%$, total hysteresis $0.1 \%$, and maximum overshoot $20 \%$ in the step size range $\pm 10 \%$.

The studied low-pressure water hydraulic positioner fulfils all these specifications, as can be seen in Figures above.

Typical problems with pneumatic positioners are a long dead time, slow response to small changes, overshoots, and danger to limit cycles.

Based on this short-term study it can be concluded that with a low-pressure water hydraulic positioner all typical problems of pneumatic positioners can be overcome.

\section{PROBLEMS}

There are no performance problems with low-pressure water hydraulics in this kind of application. Based on this study and experience gained over many years on water hydraulics, it seems that the biggest problems are the availability of suitable components, life cycle, reliability, and costs.

In this application the control valve of the positioner caused a special problem. The commercial servo valve that was used worked perfectly, and it has been used before and after these tests in many other studies. However, it is significantly too expensive. Due to this fact some studies have been conducted to find the minimum specifications for a control valve.

In this case the required dynamics of a servo valve type control valve was studied. The dynamics of the commercial servo valve was modified as shown in Figure 15. Simulated step responses are shown in Figure 16.

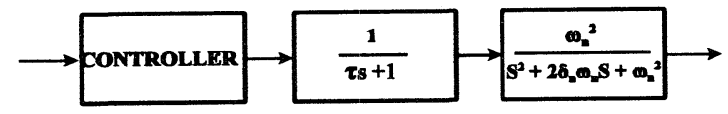

Figure 15 Modification of servo valve dynamics.

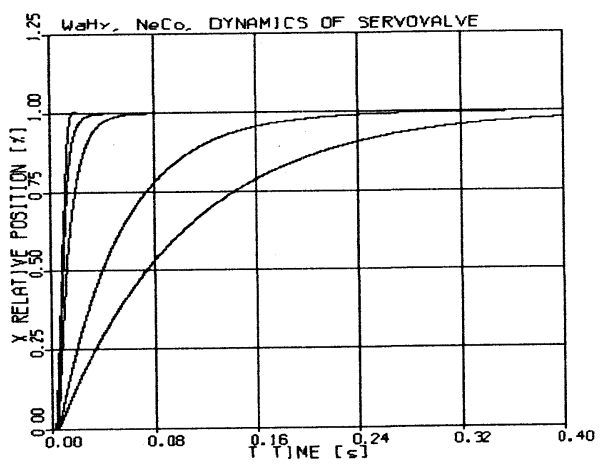

Figure 16 Step responses of the servo valve with time constants $1,5,10,50$, and $100 \mathrm{~ms}$ of the filter.

The measured step responses of the position error in both directions are shown as an example in Figure 17, when the

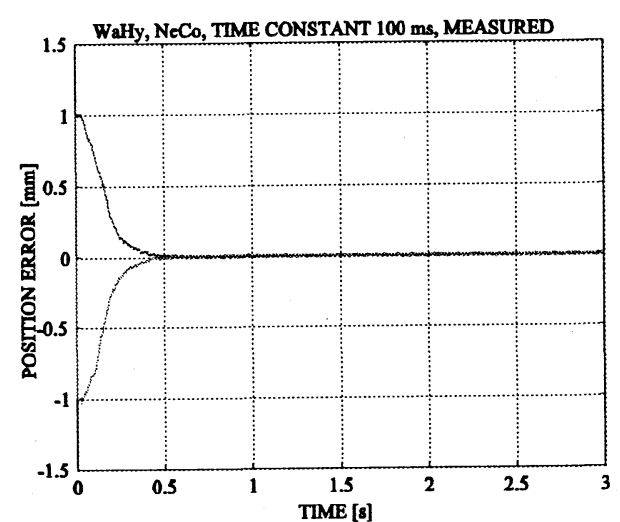

Figure 17. Measured step responses, time constant 100 ms.

filter time constant is $100 \mathrm{~ms}$. The velocity feedback inner loop is used to stabilize the dynamic behavior.

Other efforts to solve the control valve problems are presented in [3], [4], and [5].

\section{CONCLUSIONS}

According to this feasibility study the following conclusions can be made.

- Very good steady state and dynamic performance can be achieved.

- The dynamics of a control valve can be rather poor compared to typical material handling applications.

- The positioner based on commercial components is too expensive.

\section{REFERENCES}

1. Kunttu, P., Koskinen, K.T. and Vilenius, M. 1999. Low Pressure Water Hydraulics - State of the Art. The Sixth Scandinavian International Conference on Fluid Power, 26.-28. May, 1999, Tampere, Finland. pp. 67-75.

2. EnTech: Control Valve Dynamic Specifications, 1998.

3. Vuorisalo, M. \& Virvalo, T. 2000. Comparing the control methods of fast water hydraulic on/off-valves in pressure control. The $7^{\text {th }}$ Mechatronics Forum, 6th-8th September, 2000, Atlanta, Georgia, USA. 5 p.

4. Vuorisalo, M. \& Virvalo, T. 2000. Smart material actuators for fluid power valves with different pressure mediums. 9th Annual Conference on MMV, 19th-21st, September, 2000, Harvey Bay, Queensland, Australia. p. 305-313.

5. Vuorisalo, M., Virvalo, T. \& Anttonen, P. 2001. Different types of pilot stages for a water hydraulic control valve. ICFP $\nmid 2001$ April 3-5, 2001, Hangzhou, China. p. 435-439. 